\title{
CORRECTION
}

\section{Correction: A randomized trial to study the comparative efficacy of phenylbutyrate and benzoate on nitrogen excretion and ureagenesis in healthy volunteers}

Sandesh C. S. Nagamani, Umang Agarwal, Allison Tam, Mahshid Azamian, Ann McMeans, Inka C. Didelija, Mahmoud A. Mohammad and Juan C. Marini

Genetics in Medicine (2021) 23:2227; https://doi.org/10.1038/s41436-021-01099-9

Correction to: Genetics in Medicine 20:708-716 (2018); https://doi. org/10.1038/gim.2017.167; published online 12 October 2017

Unfortunately the Electronic Supplementary Material was incomplete. Figures S1, S2, and S3 were missing.

Please find the Figures below.

\section{ADDITIONAL INFORMATION}

Supplementary information The online version contains supplementary material available at https://doi.org/10.1038/s41436-021-01099-9.
Correspondence and requests for materials should be addressed to J.C.M.

Reprints and permission information is available at http://www.nature.com/ reprints 